\title{
Aedes albopictus - A New Disease Vector for Europe?
}

\author{
MAWard
}

BSc

\section{DrNRHBurgess}

BSc, PhD, MIBiol, FRES

Defence Adviser and Senior Lecturer in Entomology

Department of Entomology, Royal Army Medical College, Millbank, London SWIP 4RJ

SUMMARY: Aedes albopictus is an important and widespread vector of dengue in many tropical countries. Its eggs and larvae are readily transported in commodities, such as old vehicle tyres, to many temperate regions, where it is able to survive and breed. It could thus become a serious health threat in Europe.

\section{Introduction}

Aedes albopictus, the Asian Tiger Mosquito, is an aggressive, mobile and very plastic Culicinae mosquito.

Aedes albopictus occurs throughout the Oriental region, southeast to New Guinea and on most islands in the Indian Ocean westward to (and including) Madagascar. In China, Ae. albopictus occurs as far north as Beijing $\left(39.55^{\circ} \mathrm{N}\right)$, in Korea as far north as Seoul $\left(37.30^{\circ} \mathrm{N}\right)$, and in Japan as far north as Sendai $\left(38.16^{\circ} \mathrm{N}\right)(1)$.

Over the last few decades the range of Ae. albopictus has expanded, locally due to its ability to colonise manmade containers, and globally due to colonisation of used car tyres which have been exported from Asia to various parts of the world. Since its discovery in the United States in 1985 (2) Ae. albopictus has colonised at least seventeen States in the U.S. and can now be found in Brazil (3), Australia (4), Nigeria (5), South Africa (6), Hawaii, and the islands of the South Pacific (1).

\section{Medical importance}

Aedes albopictus is a known vector of the four strains of dengue virus in southeast Asia, the Seychelles, southern China and Japan. The mosquito can become infected transovarially as well as by feeding on an infected host (1). Ae. albopictus is often regarded as an minor vector of dengue because of the greater importance of $A e$. aegypti, with the latter usually only transmitting the more severe strains of the dengue virus and the former being able to transmit the full range of strains of dengue virus (1).

Ae. albopictus could undoubtedly become a significant vector of dengue in North and South America (1) and Australia (4). In Asia the mosquito lives in forest fringes and so can transport new arbovirus strains from the forest into local communities. The same may occur in America.

Ae. albopictus has been found to be an efficient transmitter of at least 26 human diseases (7) including, dengue, LaCrosse virus, Chikungunya virus, Japanese encephalitis, St. Louis encephalitis, Western equine encephalomyelitis, Orungo virus, Ross River virus and Yellow fever (8).

\section{Habitat}

Aedes albopictus occurs in urban areas with vegetation and breeding sites, suburban, rural and forest habitats (near the forest fringe but rarely deep in the forest) (1). Larvae may be found in a wide range of cors tainers, both natural and man-made, from tin cans to $5 \mathrm{~S}$ gallon drums, and in tree holes, bamboo stumps, rocks pools and leaf axils (1). In its adopted countries $A \&$ albopictus occurs mainly in used tyres in which water can accumulate, but it has also been found in tree holes.

\section{Biology}

Aedes albopictus egg mortality in nature is due to desiccation, predation and cold, depending on the strain of mosquito. Older eggs can survive desiccation better than newly laid eggs; temperate strains survive cold better than tropical strains. A low oxygen concentration has been found to be an important stimulus for egg hatching and several floodings may also be required (1). Eggs of temperate strains of Ae. albopictus can go into diapause, the embryos resting until warmer weather triggers further development (9). Diapause, in temperate strains, is controlled by a photoperiodic response in adult female mosquitoes - long days cause nondiapausing eggs to be laid and short days stimulate diapausing eggs (1).

High larval density and low food supply lead to high larval mortality and small adult size (due either to less $\delta$ food per larva or chemical inhibitants produced by larvae at high densities. Predators can be an important $ᄋ$ limitation to larval Ae. albopictus survival, (for example, Toxorhynchites larvae, a carnivorous mosquito, eats other larval mosquitoes). There are also parasites, such as the fungus Coelomomyces stegomyiae and the $\sigma$ ciliate Lambornella stegomyia, which increase larval $\tilde{O}$ mortality (1).

Adult Ae. albopictus rest near the ground and bite 
aggressively, attacking any exposed skin, particularly around the ankles and knees, with peaks of biting activity in the early morning and late afternoon (1). An average biting rate of 14 bites per man-hour (in Madagascar, between 16:30 and 18:30 hours) has been recorded (10). The mosquito is usually outdoor-biting and rarely bites at night. It seldom flies in windy conditions and hence wind-aided dispersal is unlikely to occur in this species (1).

Ae. albopictus is well adapted to breeding in ephemeral water pools (for example, larvae have been found in the finger holes of a bowling ball left in the rain in Chicago), the female ovipositing in a number of containers, thus increasing the chances of of fspring survival (2). The female prefers to lay her eggs above the water surface on a dark, rough and vertical substrate (1). In tyres, the eggs are laid on the inner surface; when rain fills the tyre the eggs hatch and the larvae begin to develop (2).

\section{The potential spread of Ae. albopictus}

Nawrocki and Hawley (11) estimated the potential northern range of Aedes albopictus in North America based on reports of the north Asian distribution and climatological data for Asia and America. The northern range was divided into two types - the overwintering limit and the late summer expansion range. Ae. albopictus has been found as far north as Beijing $\left(39.55^{\circ} \mathrm{N}\right)$ in China, although it probably does not overwinter there. Successful overwintering of $A e$. albopictus has been documented in Tsinan $\left(36.41^{\circ} \mathrm{N}\right)$ in
China (mean January temperature $=-1.2^{\circ} \mathrm{C}$ ), Ashikaga $\left(36.21^{\circ} \mathrm{N}\right.$ ) in Japan (mean January tempera- $\mathbb{\Phi}$ ture $=+2.4^{\circ} \mathrm{C}$ ), and Kumsa $\left(36^{\circ} \mathrm{N}\right)$ in S. Korea (mean January temperature $=-3^{\circ} \mathrm{C}$ ). Based on these data, ifo the January $0^{\circ} \mathrm{C}$ isotherm is the limit of the overwin-c? tering range for Ae. albopictus then the mosquito may have already reached its limit, in Illinois; however if the? January $-5^{\circ} \mathrm{C}$ isotherm is used as the limit of the overwintering range then $A$ e. albopictus could spread to the southern edge of Canada (11). Although abundant rainfall is not essential for Ae. albopictus establishment, $\mathbb{Q}$ low summer rainfall could limit its spread northwards. Conversely the probability of Ae. albopictus becoming established along the Pacific coast may be higher in: wetter, more northern districts (11).

Based on these estimates (i.e. Ae. albopictus covers areas where the mean January temperature is greatero than $0^{\circ} \mathrm{C}$ and where there is sufficient summer rainfall), Ae. albopictus may be able to spread throughout $\frac{1}{\omega}$ Europe, including the U.K. (Fig 1), and the discovery of this species in Geneva may be the beginning of this invasion.

\section{Conclusion}

Aedes albopictus "is an ecological generalist capate of rapid evolution and, with the aid of man, speedy cबi onization of new habitats" (1). This mosquito has ne spread into the western hemisphere due to the shipmengा of used tyres from Asia. Cargo imported into Africatis not routinely inspected for mosquitoes and therefowe other, as yet undetected, populations of Ae. albopic

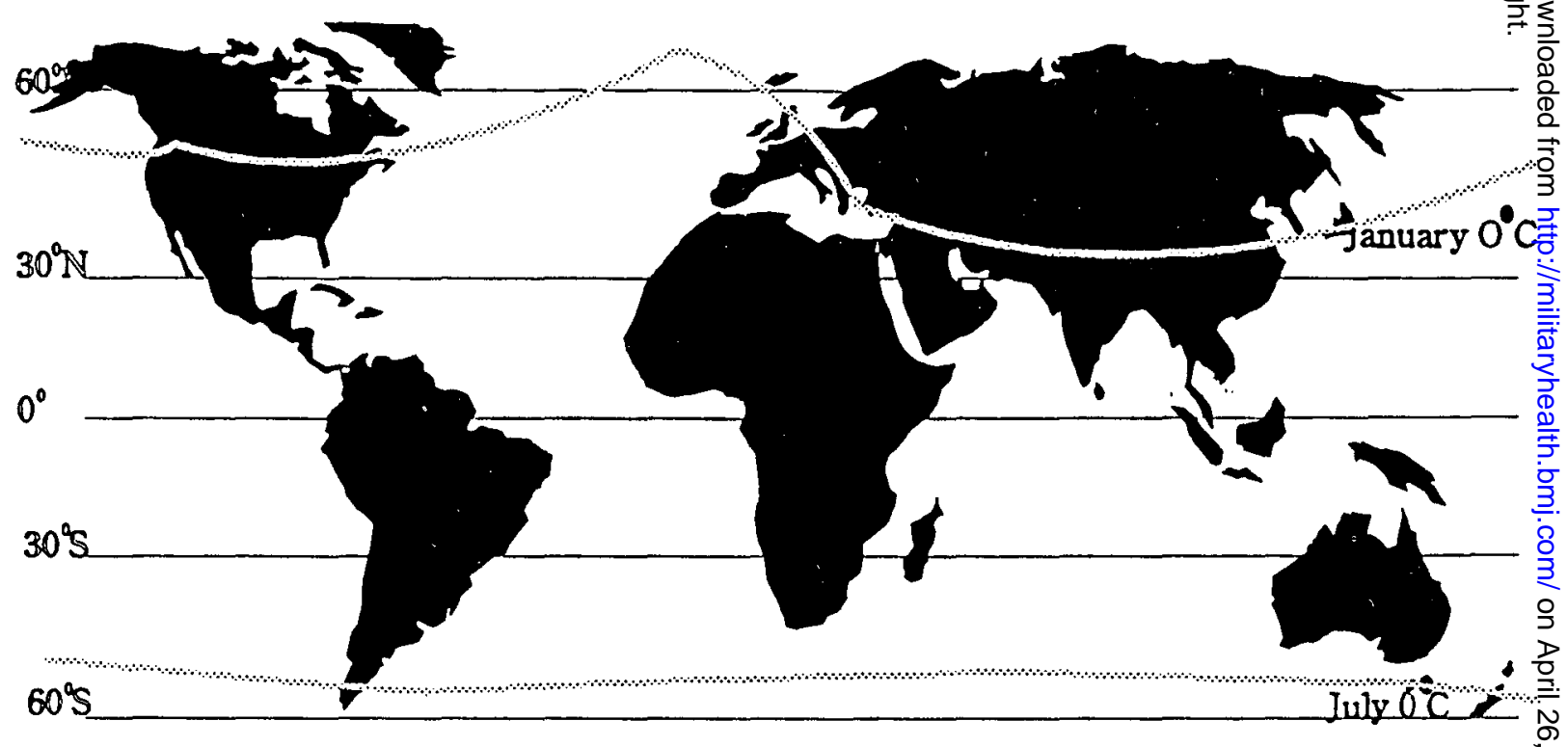

Fig 1. Mean January (northern hemisphere) and July (southern hemisphere) $0^{\circ} \mathrm{C}$ isotherms. Most of Europe actually $\mathcal{O}^{\circ}$ falls within the habitat range of Ae. albopictus (temperate strains) as described by Nawrocki and Hawley (1987). (Figure from Bartholomew (12).) 
may already exist in Africa (7). From there, the mosquito could spread into Europe where suitable habitats and an available niche for Ae. albopictus to become established, undoubtedly occur.

Dengue fever is known to have occurred in Europe, with a large outbreak in Greece in 1927-1928 affecting over one million people (13). The disease was probably introduced from Africa via migrating birds.

Thus if Ae. albopictus were to become established in Europe, dengue could become a serious European health problem and just one of a series of arboviral diseases (to which few Europeans are immune) which may be transported with Ae. albopictus, in used tyres.

\section{REFERENCES}

1. Hawley W A. The biology of Aedes albopictus. Journal of the American Mosquito Control Association 1988; 4 (suppl): 2-39.

2. Sprenger D, Wuithiranyagool T. Houston's tiger tale. Pest Control 1989; March 1989: 84-86.

3. Forattini O P. Identificacao de Aedes (Stegomyia) albopictus no Brasil. Rev Saude Publica 1986; 20: 244-245.

4. Kay B H, Ives W A, Whelan P I, Barker-hudson P, Fanning I D and Marles E N. Is Aedes albopictus in Australia? Med J Aust 1990; 153 (1): 31-34.
5. Anon. Aedes albopictus introduction into continental Africa. Morbidity and Mortality Weekly Report 1991; 40 (48): 836-838.

6. Cornel A J, Hunt R H. Aedes albopictus in Africa? First records of live specimens in imported tyres in Cape Town. Journal of the American Mosquito Control Association 1991; 7 (1): 107-108.

7. SHAHEEN L. Illinois evicts mosquitoes. Pest Control 1992; March 1992: 36-40.

8. Shroyer D A. Aedes albopictus and arboviruses: a concise review of the literature. Journal of the American Mosquito Control Association 1986; 2 (4): 424-428.

9. Hall R. The tiger is loose. Pest Control 1988; Feb 1988: $41-44$

10. Fontenille D, Rodhain F. Biology and distribution of Aedes albopictus and Aedes aegypti in Madagascar. Journal of the American Mosquito Control Association 1989; 5 (2): 219-225.

11. Nawrocki S J, Hawley W A. Estimation of the northern limits of distribution of Aedes albopictus in North America. Journal of the American Mosquito Control Association 1987; 3 (2): 314-317.

12. Bartholomew J C. World Atlas (12th Ed.) 1982; John Bartholomew \& Son Ltd.: Edinburgh.

13. SNOw K R. Medically important mosquito-borne arboviruses in Europe with special reference tot Britain. Bulletin of the Royal Entomological Soci-O ety 1991; 15 (1): 12-20. 